\title{
Digitally Controlled Integrated Electronic Ballast with Dimming and Power Factor Correction Features
}

\author{
C. Aguilar-Castillo* ${ }^{* 1}$, C.D. García-Beltrán ${ }^{1}$, C. Morcillo-Herrera ${ }^{2}$ \\ ${ }^{1}$ Centro Nacional de Investigación y Desarrollo Tecnológico \\ Interior Internado Palmira SN \\ Cuernavaca, Morelos, México \\ *aguilar@cenidet.edu.mx \\ ${ }^{2}$ Universidad Tecnológica Metropolitana \\ Calle 115 No. 404, Colonia Santa Rosa \\ Mérida, Yucatán, México
}

\begin{abstract}
This paper presents a digitally controlled integrated electronic ballast with dimming and power factor correction features. The control circuit is based on a low-cost PIC16C71 microcontroller where the different strategies for energy saving have been implemented. The ballast is operating in closed loop achieving tight lamp current regulation through a digital Proportional-Integral algorithm. The integrated power stage is based on a frequency-controlled single-switch boost rectifier plus a half-bridge series resonant parallel loaded inverter sharing one power switch. The single-switch boost rectifier works in discontinuous inductor current mode with automatic power factor correction. Detailed analysis of the power stages and experimental results using 42-watt electronic ballast are presented.
\end{abstract}

Keywords: Electronic ballast, lighting control, active power factor correction, and digital control.

\section{RESUMEN}

Este artículo presenta un balastro electrónico integrado controlado digitalmente con características de control de intensidad luminosa y corrección del factor de potencia. El circuito de control está implementado en un microcontrolador de bajo costo (PIC16C71), en donde se han implementado distintas estrategias de ahorro de energía. El balastro opera en lazo cerrado con control preciso de la corriente de la lámpara usando para ello un algoritmo de control proporcional - integral. La etapa de potencia está basada en rectificador Boost integrado a un convertidor resonante serie en medio puente, compartiendo un interruptor de potencia. El rectificador Boost opera con corriente discontinua y por tanto obtiene corrección del factor de potencia de manera automática. El artículo presenta el análisis detallado de un balastro electrónico para una lámpara de 42 watts, incluyendo resultados experimentales.

\section{Introduction}

In the typical operation of the fluorescents lamps, a voltage applied to their terminals warms up the cathodes of the lamp, causing electrons release from one cathode and attraction of these electrons by the other cathode. These electrons flow is called discharge [1]. In their way towards the other cathode, the electrons hit mercury atoms, producing a double effect: on the one hand, the emitted electrons acquire high speeds, increasing the electric discharge, and on the other hand, the valence electrons of these atoms absorbs more energy, which is later released, emitting photons. Due to this avalanche behavior, the emitted light has different wavelengths, which gives place to a discontinuous light spectrum. Negative impedance is an interesting behavior in this type of lamps.

This behavior is associated to the triggering of collisions and electrons liberation thus it is very important to control this behavior to avoid short circuits in the lamp. The solution to avoid lamp short circuit is to use a device named ballast.

Ballasts for fluorescent lamps are devices that allow excitation of the lamp cathodes. This task is traditionally made by electromagnetic ballasts, which represent the $85 \%$ of the market; on the other hand, electronic ballasts represent only the $15 \%$. A fundamental difference between these types of ballasts is the excitation frequency: whereas the electromagnetic ballasts work at line frequency $(60 \mathrm{~Hz})$, the electronic ballasts work above $20 \mathrm{kHz}[2,3,4]$. 
At the present time, highly efficient electronic ballasts are preferred over conventional electromagnetic ballasts to supply fluorescent lamps due to their excellent features. Some of these features include high frequency operation (no stroboscopic phenomenon, higher efficacy, lighter weight, smaller size, etc), possibility to implement dimming (energy saving), reduction of harmonic currents (less power consumption), etc. Despite the features and energy efficiency gains, the cost of the ballast increases. For these reasons, numerous research studies are being conducted in order to reduce production costs and to make the electronic ballasts a more attractive alternative.

There are many topologies of electronic ballasts. The early ones consisted of full-wave rectifier bridges, followed by a high frequency invert stage. This type of ballast had the disadvantage that it presented a high crest factor and blinking at low voltages. In order to solve these problems, some topologies included a filtering capacitor; nevertheless, this element caused a high harmonic content and a low power factor. The inclusion of this capacitor made an extra CD/CD stage necessary for power factor correction and elimination of harmonic content [5]. Some consequences of these multiple-stage topologies are low-energy efficiency and high economic cost.

The dimming capacity in electronic ballasts for fluorescent lamps has been quickly increased due to high potential of energy saving and the comfort to users but it represents new challenges in the design of electronic ballast [6].

New topologies propose integrated schemes which share electronic components, essentially the power switches; however, this integration increases complexity of the control system due to the coupling between electronic stages. With intentions of integrating dimming and power factor correction, some DC-DC converters topologies with boosting characteristics are used since they correct the power factor in a natural way when they operate in discontinuous inductor current mode. Some alternatives for this type of strategies are single-stage electronic ballasts based on boost converters $[7,8,9]$, ballasts with boost converter with the inductance at the AC side [10], ballasts based on a buck-boost converter [11], ballasts with a flyback converter [12] and ballasts based on a Cuk converter [13].

In some countries, it is necessary that ballasts meet some standards or recommendations related to harmonics current levels induced in the utility line, such as the IEC 61000 3-2 norm. The typical approach to fulfill this is to use two different stages. The first one could be a low-harmonic input current AC-DC converter, and the second one, a highfrequency DC-AC converter. The main drawbacks of this approach are the high cost and complexity of the control circuit. Integrated electronic ballasts have been proposed in order to keep the advantages of high frequency, high-power-factor electronic ballasts, while keeping costs down [1419]. The main idea in these approaches is to share the power switches of the two stages; however, integrated power stages mean higher complexity in the control circuit design. This comes from the reduction of the number of control variables and the coupling between both power stages.

Recently, microprocessor-based control circuits have undergone enormous evolution, gaining popularity due mainly to their increased versatility. Typical microcontroller units include all the necessary features to implement a whole control system: processing unit, RAM, ROM, I/O peripherals, and some integrate analog-to-digital converters or PWM modules. The use of microprocessors in electronic ballasts became interesting because they can implement different strategies for energy saving: dimming, daylight control, light level according to the task, etc. Some microprocessor-based control electronic ballasts have been proposed possessing functions such as energy saving, supervisory task, or dimming features. In [20], the microcontroller performs supervisory and control device functions in a twostage emergency lighting. In [21], an energy saving illuminating system based on a Lon Work technology is presented. In this case, the power stage is a two-stage approach. A fuzzy logiccontrolled electronic ballast with dimming function is presented in [22]. In this approach, a bifrequency control of a half-bridge series-resonant parallel-loaded (SRPL) inverter is introduced. The ballast features a low power factor. In these previous works, a two-stage approach is involved or no power factor correction is included. 
This paper presents a microcontroller-based control for an integrated electronic ballast (IEB) which features dimming, low-harmonic input current and high power factor. In this case, the microcontroller performs all of the tasks of the system: it converts $A / D$, it evaluates the control strategy and it brings the signal to control the power stage (frequency based control). The implemented control is a digital ProportionalIntegral (PI) controller. The paper addresses the analysis of the power stage and the design of the digital control. Also, experimental results of a laboratory prototype are included.

\section{Proposed system}

The proposed electronic ballast system is shown in Figure 1. It consists of an IEB and a microcontroller-based control system. The integrated electronic ballast features high power factor, low harmonic input current and high frequency AC output voltage. The power stage is based on a single-switch boost rectifier followed by a half-bridge SRPL inverter. These stages share power switches reducing one power switch and one control circuit. As result, the number of components is reduced and the cost is lower. The single-switch boost rectifier works in discontinuous conduction mode (DCM) with automatic power factor correction. The ballast is controlled by frequency modulation; that is, a toroidal core senses the current through the lamp, this information is taken by the controller where it is compared with the current reference (dimming setpoint). The controller establishes the deviation respecting the dimming set and gives a frequency signal with near $50 \%$ duty cycle. The controller keeps the switching frequency constant during the whole line period. This is important in order to keep a high power factor and low total harmonic distortion on the input current.

The control circuit is based on a microcontroller that achieves regulated output wattage (keeping constant lamp current) and offers dimming capacity. The selected microcontroller was an 8-bit microcontroller based on RISC architecture which provides software and hardware design for embedded control. It features ROM, RAM, analogto-digital converters, timers, etc. The

microcontroller gets the lamp current from the current probe and makes the necessary calculations to establish the switching frequency. The control law implemented in the microcontroller is a digital proportional-integral (PI) approach. The control circuit includes a MOSFET driver that works as interface between the microcontroller and the power stage. In the next paragraphs, a detailed description of the system is presented.

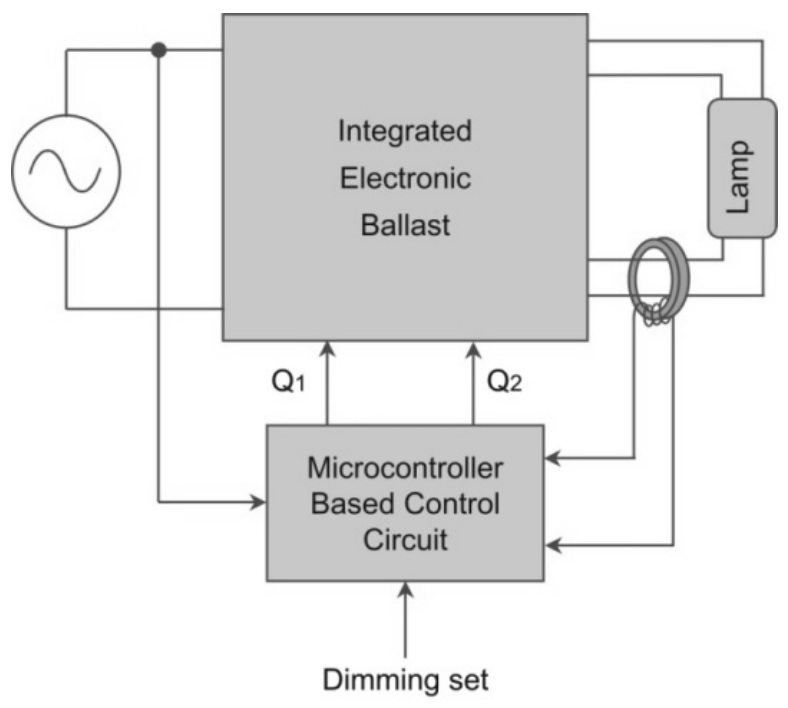

Figure 1. Functional block of the proposed electronic ballast. 


\section{Digitally Controlled Integrated Electronic Ballast with Dimming and Power Factor Correction Features, C. Aguilar-Castillo et al., 295-309}

\section{Integrated electronic ballast}

Figure 2 shows the derivation of the proposed electronic ballast. Figure $2 a$ shows a two-stage approach based on a single-switch boost rectifier followed by the half-bridge SRPL inverter. As can be seen, the switch of the boost converter (Q1) and the lower switch of the half-bridge inverter (Q3) share the same node and due to the fact that they can be switched synchronously, they can be merged in only one power switch (Q1 in Figure $2 \mathrm{~b})$. The resulting single-stage electronic ballast is shown in Figure 2b. In this case, switch Q1 carries both the boost current and half of the inverter current. Now the control circuits are also merged in a single strategy; however, the controlled parameter is reduced to one as well. In illuminating systems, constant lamp power is the most importance variable so it must be selected as the controlled variable. The switching frequency has been selected as control variable for the lamp power regulation. Another possibility is to control the Q1 switch duty cycle but this variable does not allow full control under both input voltage and different dimming level variations. A control strategy based on variable switching frequency and variable duty cycle could also be used but the control algorithm becomes very complicated.

In the proposed electronic ballast, the power stages are linked by a bulk capacitor formed by $\mathrm{C}_{a}$ and $C_{b}$. At the switching frequency, the capacitor voltage could be considered as a constant voltage source, then the ballast can be analyzed as two separated stages. In the following, these two stages are analyzed separately.

\section{A. Single-switch boost rectifier as power factor corrector}

The single-switch boost rectifier works as AC-DC converter with low harmonic input current. This is achieved by operating in discontinuous inductor current mode. Figure 3 shows the equivalent circuits of the proposed electronic ballast during the positive and the negative semi-cycle on the input voltage. In this figure, the inverter has been considered like a constant impedance $Z_{L}$.

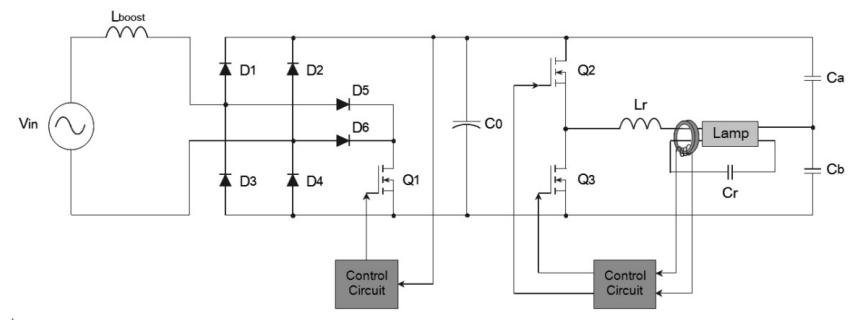

(a)

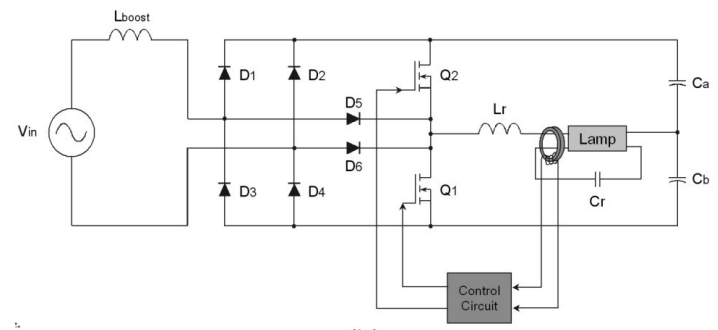

(b)

Figure 2. Derivation of the proposed ballast. (a) Two-stage approach, (b) Single-stage approach. 


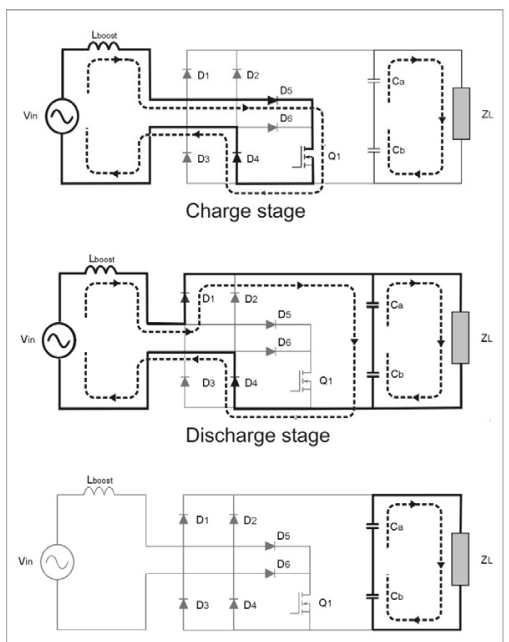

Idle stage Dead time
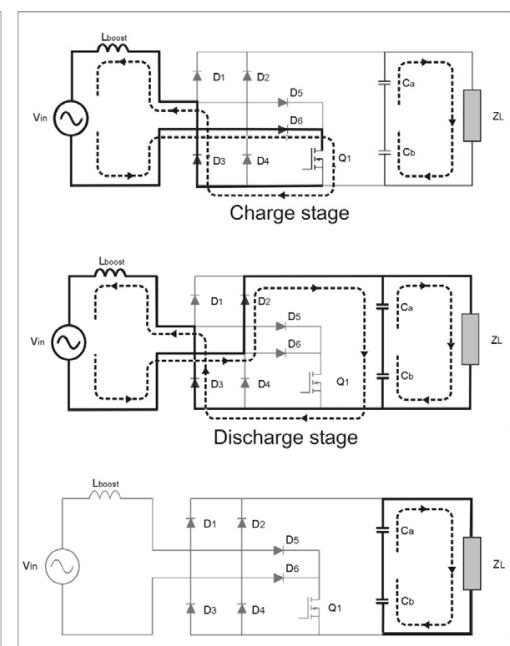

Idle stage Dead time

Figure 3. Equivalent circuits of the single switch boost rectifier. (a) Positive semi-cycle of the input voltage. (b) Negative semi-cycle of the input voltage.

Figure 4 shows the idealized boost inductor current during both positive and negative semi-cycle. In this figure, the switching frequency is shown to be four times higher than the line frequency but, actually, the switching frequency is much higher than the line frequency $(100 \mathrm{kHz} v \mathrm{vs} 60 \mathrm{~Hz})$.

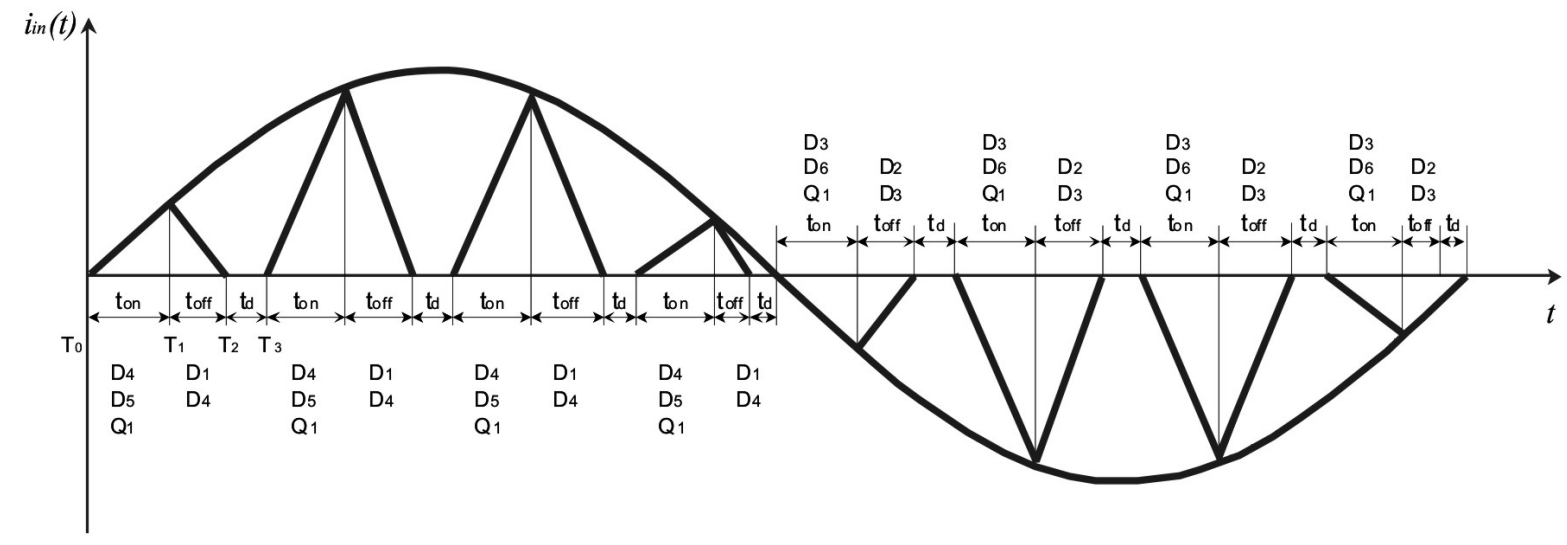

Figure 4. Boost inductor current. 
During the positive semi-cycle, the operation is as follows:

[T0-T1] Charge stage ( $t_{\text {on }}$ time). This stage begins when the switch is turned on. During this period, the boost inductor current rises in a linear way (considering constant voltage at the switching frequency), expressed by

$$
i_{\text {Lboost }}=\frac{\left|v_{\text {in }}(\omega t)\right|}{L_{\text {boost }}} t
$$

The inductor current is carried by diodes $\mathrm{D}_{4}$ and $D_{5}$, and switch $Q_{1}$.

[T1-T2] Discharge stage ( $t_{\text {off }}$ time). During this time the boost inductor current falls in a linear way expressed by

$$
i_{\text {Lboost }}=\frac{\left|v_{\text {in }}(\omega t)\right|-V_{0}}{L_{\text {boost }}} t
$$

In this case the discharge current is conducted by diodes $D_{1}$ and $D_{4}$.

[T2-T3] Idle stage (Dead time). There is a third equivalent circuit named the idle stage that begins when the inductor current reaches zero and it ends when the switch is turned on again to begin a new switching period.

The operation during the negative semi-cycle is similar but now the trajectories of the current are different, as shown in Figure 3.

The peak current of the boost inductor is given by

$$
i_{L_{\text {Bost }} \text { peak }}=\frac{\left|v_{\text {in }}(\omega t)\right|}{L_{\text {Boost }}} t_{\text {on }}
$$

where $t_{o n}$ is considered constant during the whole input voltage period. The discharge time depends on the input voltage and is given by

$$
t_{\text {off }}(t)=\frac{\left|v_{\text {in }}(\omega t)\right|}{V_{0}-\left|v_{\text {in }}(\omega t)\right|} t_{\text {on }}
$$

Averaging the input current, we have:

$$
i_{a v}(\omega t)=\frac{D^{2} V_{0}}{2 L_{\text {Boost }} f_{s}}\left(\frac{M \sin (\omega t)}{1-M \sin (\omega t)}\right)
$$

where

$$
\begin{array}{ccl}
\multicolumn{2}{c}{M=} & \frac{V_{g}}{V_{0}}
\end{array}
$$

From (5), it is possible to conclude that the singleswitch boost rectifier features the same characteristics as the conventional DCM boost converter when it is applied to the power factor correction.

The input power could be expressed as

$$
P_{i n}=\frac{1}{\pi} \int_{0}^{\pi} v_{i n}(\omega t) i_{a v}(\omega t) d(\omega t)
$$

Substituting (5) and (6) into (7), the input power is

$$
P_{i n}=\frac{D^{2} V_{g}^{2}}{2 \pi L f_{s}} y
$$


where

$$
\begin{aligned}
& y=\int_{0}^{\pi}\left(\frac{\sin ^{2}(\omega t)}{1-M \sin (\omega t)}\right) d(\omega t) \\
& y=-\frac{2}{M}-\frac{\pi}{M^{2}}+\frac{1}{M^{2}}\left(\frac{2}{\sqrt{1-M^{2}}}\right)\left(\frac{\pi}{2}-a \tan \left(-\frac{M}{\sqrt{1-M^{2}}}\right)\right)
\end{aligned}
$$

In this analysis, a constant duty cycle has been considered. To assure this, it must satisfy the following equation:

$$
D_{\max } \leq(1-M)
$$

In the proposed circuit, the duty cycle is kept constant close to 0.47 and the control is performed through a variable switching frequency, then equation (11) becomes:

$$
V_{0} \geq 1.89 V_{g}
$$

From this equation, the output voltage must be at least 1.89 times peak input voltage in order to get a high power factor, then this topology could be appropriate in low voltage range, e.g., American utilities (110-120 Volts RMS).

\section{B. The Inverter stage}

Capacitors $C_{a}$ and $C_{b}$ (see figure $2 b$ ) have been selected large enough to be considered as voltage sources, then the inverter input voltage is constant over a switching period; hence, the half-bridge SRPL inverter can be simplified to the very well known resonant circuit shown in Figure 5.

$$
V_{0} \geq 1.89 V_{g}
$$

$$
f_{o}=\frac{1}{2 \pi \sqrt{\operatorname{LrCr}}}
$$

$$
Z=\sqrt{\frac{L r}{C r}}
$$

$$
Q=\frac{Z_{L A M P}}{Z}
$$

$$
\omega=\frac{\omega_{s}}{\omega_{o}}
$$

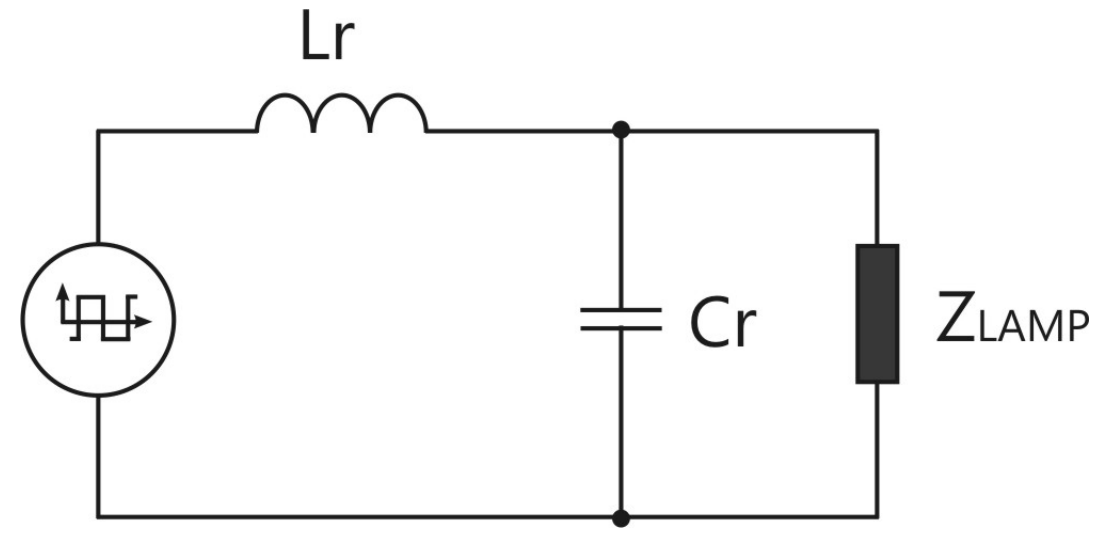

Figure 5. Simplified circuit of the half-bridge SRPL inverter. 


\section{Digitally Controlled Integrated Electronic Ballast with Dimming and Power Factor Correction Features, C. Aguilar-Castillo et al., 295-309}

where

$\omega_{s}=2 \pi f_{s}$,

$\omega_{0}=2 \pi f_{0}$

$f_{o}=$ Undamped natural frequency,

$Z=$ Characteristic impedance,

$Q=$ Quality factor,

$\omega=$ Normalized frequency.

The input impedance is given by

$Z_{i n}=j \omega_{s} L+\frac{Z_{\text {LAMP }} \cdot\left(1 / j \omega_{s} C_{r}\right)}{Z_{\text {LAMP }}+\left(1 / j \omega_{s} C_{r}\right)}=Z \sqrt{\frac{\omega^{2}+Q^{2}\left(\omega^{2}-1\right)^{2}}{1+\omega^{2} Q^{2}}}$

The lamp voltage is

$$
V_{\text {LAMP }}=\frac{\sqrt{2} V_{0}}{\pi} \frac{1}{\sqrt{\left(\omega^{2}-1\right)^{2}+\frac{\omega^{2}}{Q^{2}}}}
$$

The phase of the inductor current is

$$
\theta=\tan ^{-1}(\omega Q)-\tan ^{-1}\left(\frac{\omega}{Q\left(1-\omega^{2}\right)}\right)
$$

From (17), the resonant current is obtained:

$$
I_{L r}=\frac{\sqrt{2} V_{0}}{\pi Z_{i n}}
$$

Using (17) and (19), the input power of the inverter semi-stage can be expressed as

$$
P_{i n v}=\frac{2 V_{0}^{2}}{\pi^{2} Z_{i n}} \cos \theta
$$

Assuming no losses in the inverter semi-stage, then

$$
P_{i n v}=P_{L A M P}
$$

As it had been shown, the lamp power depends directly on the DC link voltage and the switching frequency, then the converter can be controlled by the switching frequency; however, the DC link voltage changes with switching frequency variations too, thus the DC link voltage will not be constant under input voltage variations and for different dimming sets.

\section{Microcontroller based control circuit}

The control system goal is to keep constant lamp power under perturbations in the system, such as input voltage variations. The main tasks of the control system are embedded in a microcontroller unit that includes all the necessary tools. The user, according to the tasks that are being performed, sets the lamp power level through a signal that is

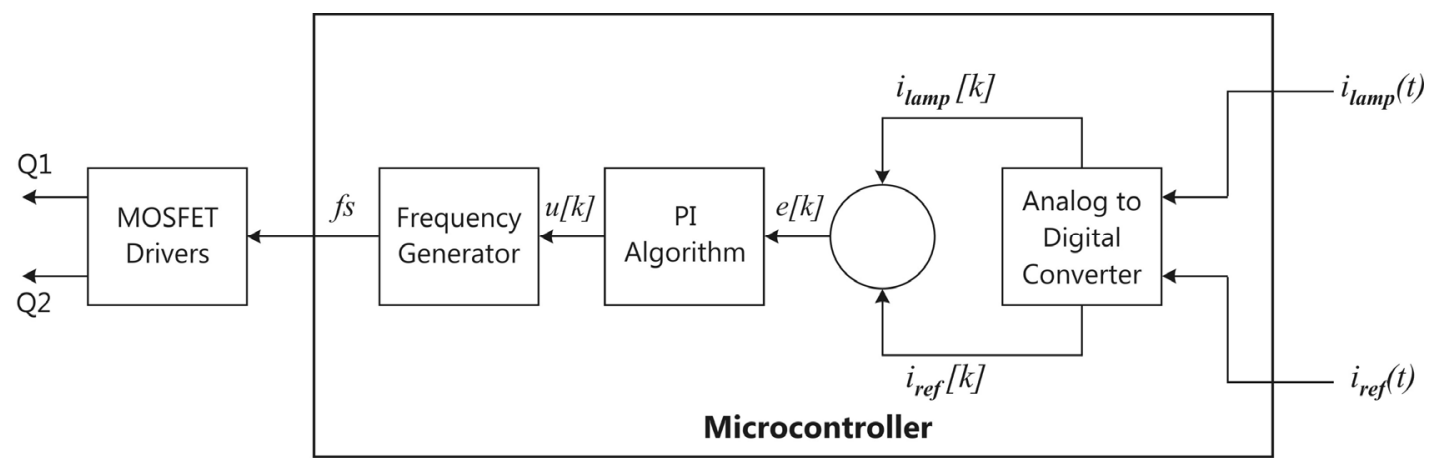

Figure 6. Functional blocks of the microcontroller based control circuit. 
sent to the microcontroller. The microcontroller also senses the present lamp current through a toroidal core-based current sensor. Using this measure, the microcontroller establishes the appropriate switching frequency of the power switches $Q_{1}$ and $Q_{2}$. The control circuit includes a power MOSFET driver which supplies the necessary current to turn on the switches. The functional blocks of the control circuit are shown in Figure 6.

The implemented control law was a digital $P I$ algorithm. In the following, the differences between the equations are derived from the continuous form of the PI algorithm (23):

$$
D(s)=\frac{u(s)}{e(s)}=K_{p}\left(1+\frac{1}{T_{I} s}+T_{D} s\right)
$$

where $K_{p}$ is the proportional gain and $\mathrm{T}_{1}$ the integral time.

Therefore, using the inverse Laplace transform, the differential equation relating $u(t)$ and $e(t)$ is

$$
\dot{u}=K_{p}\left(\dot{e}+\frac{1}{T_{I}} e\right)
$$

Finally, using the Euler's method to approximate (24), the approximated difference equation is obtained:

$$
\frac{u[k]-u[k-1]}{T}=K_{p}\left[\frac{e[k]-e[k-1]}{T}+\frac{1}{T_{I}} e[k]\right]
$$

where $\mathrm{T}$ is the sampling period.

Rearranging terms:

$$
u[k]=u[k-1]+\Delta u
$$

where

$$
\Delta u=K_{p} \Delta e+K_{i} e[k]
$$

$$
\Delta e=e[k]-e[k-1]
$$

and

$$
K_{i}=\frac{K_{p} T}{T_{I}}
$$

Equation (26) represents the digital implementation of the PI controller.

\section{Experimental results}

An experimental prototype of the proposed digitally controlled IEB was built with the following specifications:
- Lamp wattage

- Lamp current

- Lamp voltage

- Input voltage

- Dimming
42 watts.

$320 \mathrm{~mA}$.

130 volts RMS

$100-140$ volts RMS.

$30-100 \%$ (lamp current).
The prototype was implemented as shown in Figure $2 \mathrm{~b}$. A line filter was added in order to get the low frequency components of the input current. The microcontroller used was the PIC16C71 [23]. Figure 8 shows the flow chart for the control program execution. The program includes a step for cathodes heating that increases lamp life. The microcontroller takes the average of eight lamp current readings in order to reduce the occurrence of outliers. Taking this average, it computes the error between this value and the current set-point. The error goes to the PI algorithm which computes the correct switching frequency. The PI controller needs to be tuned based on the dynamic characteristics of the system. One possibility is to tune these parameters by means of the mathematical model of the whole system to meet both the steady state and the transient requirements in closed loop; however, the lamp is a nonlinear system and obtaining an accurate model of the system is very difficult. Another possibility to tune the $\mathrm{PI}$ controller is by using Ziegler-Nichols rules. This method is an experimental approach based on the system response under a step excitation. This method was selected to tune the $\mathrm{PI}$ controller. After some testing, the parameters were obtained and the control was programmed in the microcontroller according to the flow chart shown in Figure 7. 


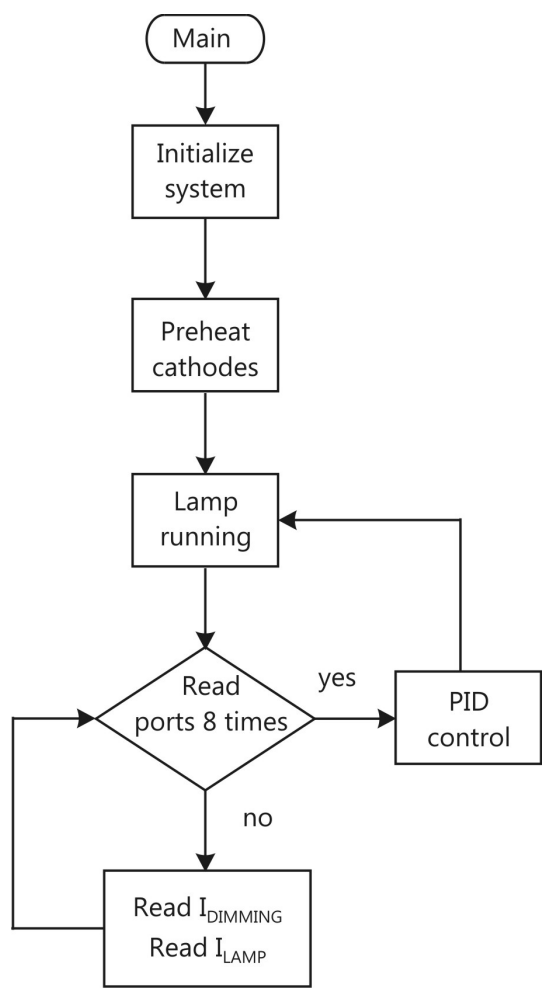

Figure 7. Flow chart for the programming control.

Figure 8a shows the experimental input voltage and current waveforms of the electronic ballast under full load, for 120 volts in the input voltage, and Figure $8 \mathrm{~b}$ shows the low frequency spectrum of the input current. As can be seen, the current and voltage waveform are in phase and the current presents low distortion. The spectrum shows the first harmonics where it is easy to verify that they meet the related harmonic standard.
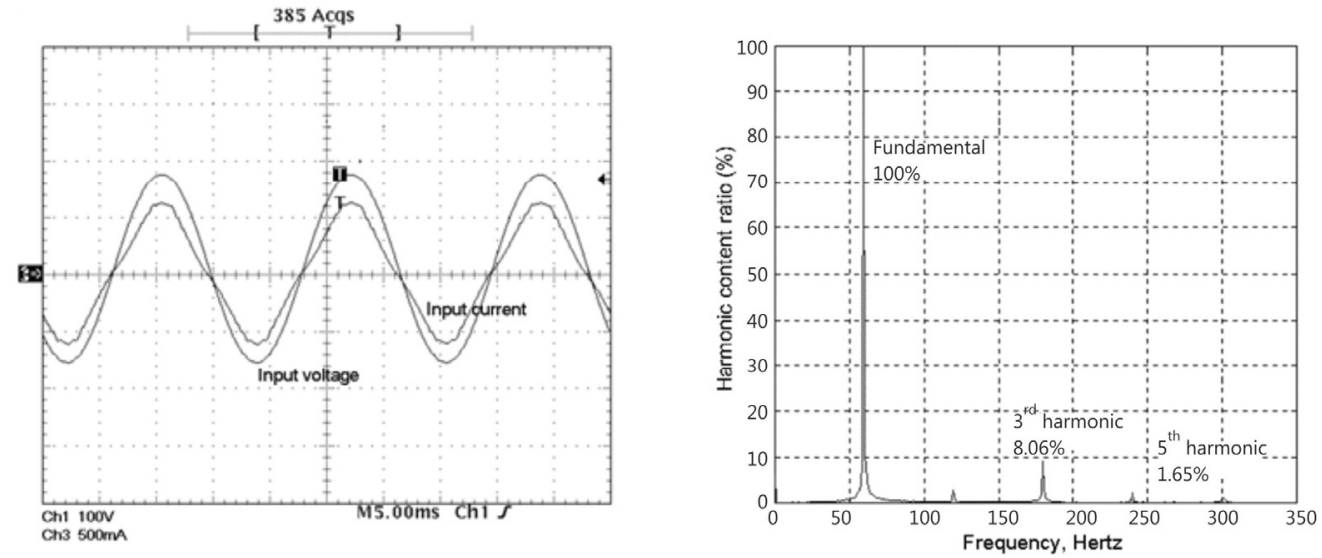

Figure 8. (a) Input voltage and current waveforms under full load condition. (b) Low frequencv spectrum of the input current. 

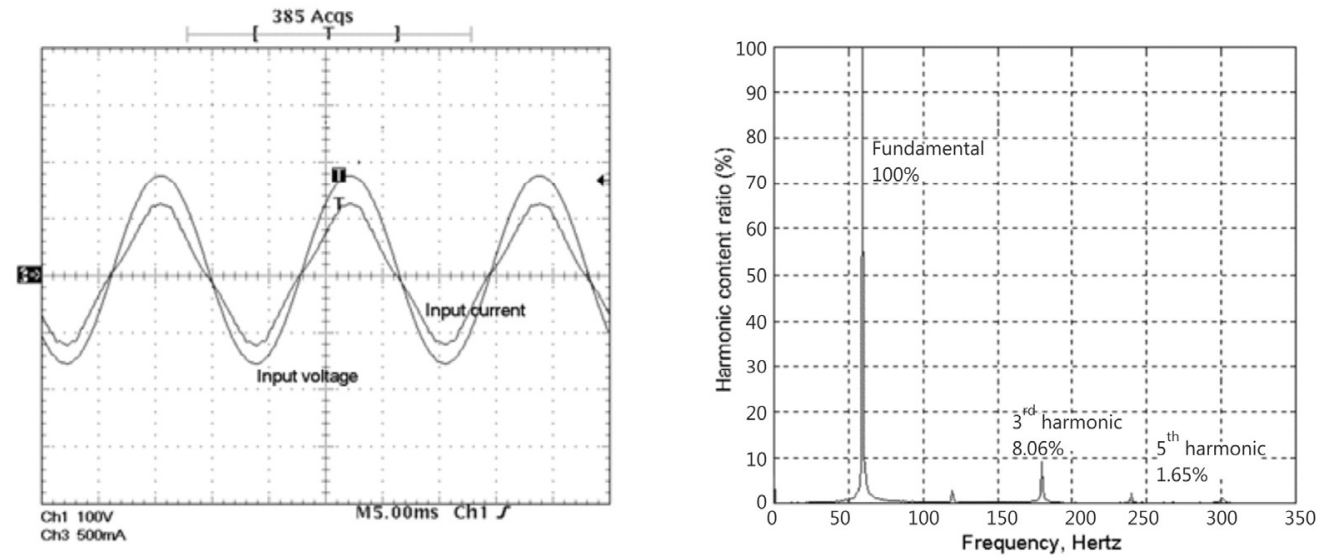

Figure 9. THD and power factor of the ballast for full load under input voltage variation.

Figure 9 shows the power factor and the total harmonic distortion (THD) under input voltage variation for full load. The obtained values fulfill the harmonic standards in the whole input voltage variation.
Lamp current under different conditions of the input voltage and dimming are shown in Figure 10. Figure 10 a shows a case where maximum switching frequency is experimented, whereas Figure $10 \mathrm{~b}$ shows the case of lower switching frequency.
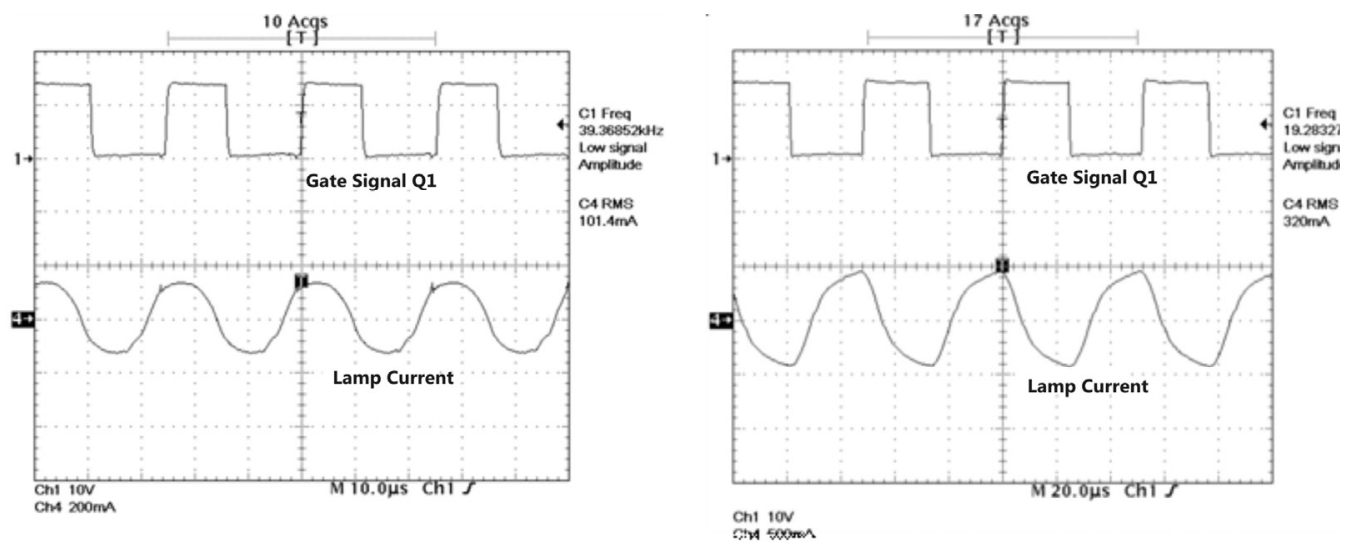

Figure 10. Lamp current under different dimming and input voltage conditions. (a) Dimming 30\%, input voltage 140 volts RMS. (b) Nominal lamp power. input voltaqe 100 volts RMS. 


\section{Digitally Controlled Integrated Electronic Ballast with Dimming and Power Factor Correction Features, C. Aguilar-Castillo et al., 295-309}

By simplification in the control, the lamp current was selected as the controlled variable. This is an indirect control of the lamp power, however, this relation is not linear but it is valid for a given operation range. Another possibility is to sense both the lamp voltage and current, and to evaluate the lamp power. As the system can be actualized every half or complete line cycle (or even more), this does not entail any complications. In that case, the extension of the program can be larger and more memory may be necessary. Figure 11 shows variations in the lamp current under input voltage variations for different dimming sets. As can be seen, no significant variations occur by input voltage variations, in fact, no light variations were perceived during experimentation. Figure 12 shows the lamp power under input voltage variation for different dimming sets. Similar to lamp current, no light variation was observed.

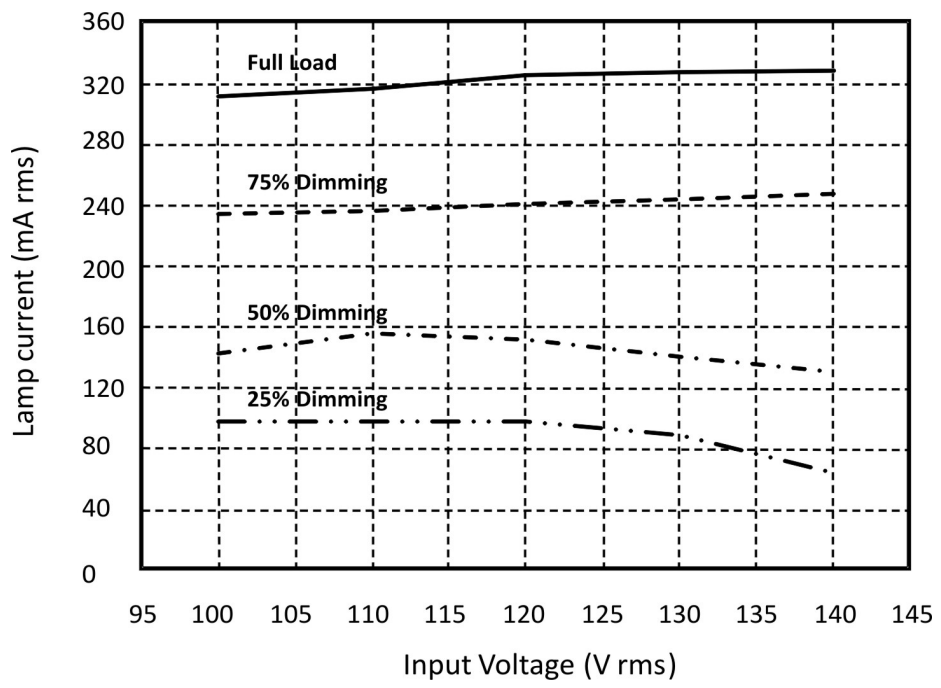

Figure 11. Lamp current for input voltage variations and different dimming scenarios.

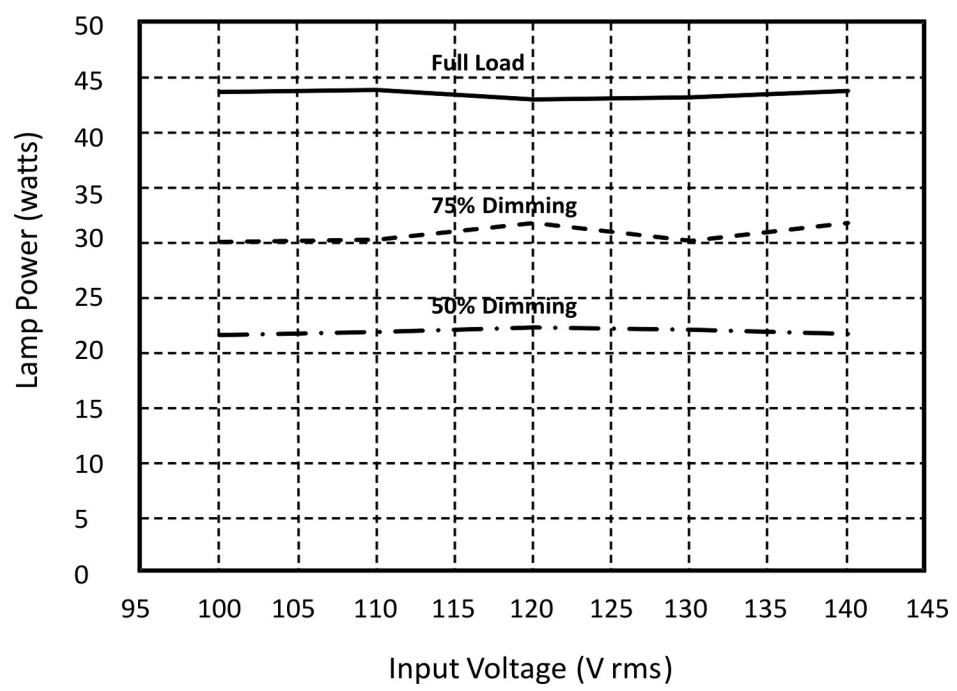

Figure 12. Lamp power for input voltage variations and different dimming scenarios. 


\section{Conclusions}

This paper presents a new integrated electronic ballast for supplying fluorescent lamps. The new topology integrates the single-switch boost rectifier and the half-bridge series resonant parallel loaded inverter. The introduced ballast features a high power factor, low harmonic input current and allows lamp power control (dimming). The involved topologies share one power switch reducing component count and cost

Experiments with different dimming settings showed that the power factor was always over 0.99 , indicating that almost all demanded power was used. In relation to harmonics, it was possible to obtain $12.3 \%$ THD in the worst case. Third and fifth harmonics where maintained under the IEC1000-3-2 C class requirements; even in the worst case, the harmonics were always under the $50 \%$ of the highest limit allowed in the standard. The efficiency of the integrated ballast was maintained between the $86 \%$ and $91 \%$, depending on the dimming setting.

The control circuit is more complicated due to interactions of the power stages. A microcontrollerbased control circuit is proposed which performs all the tasks of the control. Microcontroller-based controls have proven to be excellent alternatives for illumination systems because they permit implementation of different alternatives for energy saving. The current challenge of using microcontrollers in ballast applications is the cost. The microcontroller used is the PIC16C71, which is a low-cost 18-pin IC.

An experimental prototype was built and tested. The obtained results show good features with respect to the power factor and the total harmonic distortion on the input current, which meets the related standards. In this first approximation, a lamp current-based control was adopted for simplicity but a lamp power control is also possible due to the versatility of the microcontroller. The ballast is capable of controlling the lamp current up to $30 \%$ of the nominal current by using a simple proportional-integral approach showing good regulation under input voltage variations.

\section{References}

[1] Meyer, C., Nienhuis, H., Discharge Lamps, Philips Technical Library, 1988

[2] Vázquez, R., Analysis of resonant structures with a single transistor like electronic ballast with high power factor, Master thesis, National Center of Investigation and Technological Development, (CENIDET), Cuernavaca, Mor. Mexico, 1999.

[3] Ruiz, A., Integrated Electronic Ballast with active power factor correction, Master thesis, National Center of Investigation and Technological Development, (CENIDET), Cuernavaca, Mor. Mexico, 1999.

[4] Hammer, E., McGowan, T., Characteristics of Various F40 Fluorescent Systems AT $60 \mathrm{~Hz}$ and High Frequency, IEEE, Transactions on Industrial Applications, Vol. 21, Not 1, pp 11-16, 1985

[5] Spangler, J., Behera, A., Power Factor correction for Used Fluorescent Lamp Ballast, IEEE, PESC'90, pp 1836-1841, 1990.

[6] Trostl, A., Self configuring dimming interface for fluorescent lamp ballasts, Conference Record of the 2001 IEEE Industry Applications Conference, 2001.Thirty-Sixth IAS Annual Meeting., vol.2, no., pp.906-911 vol.2, 30 Sep-4 Oct 2001.

[7] Blanco, C., Alonso, M., Lopez, E., Calleja, A., Rico, M., A Single stage Fluorescent Lamp Ballast with high to power Factor, IEEE, APEC'96, 1996.

[8] Wu, T. F., Chiang, M. C., Chang, B., Analysis and Design of to High Power Factor, Single stage Electronic Ballast with Dimming Feature, IEEE APEC'97, 1997

[9] Srinvasan, R., Oruganti, R., A unit Power Converter Factor using Half-Bridge Boost Topology, IEEE, Transactions on Power Electrónics, vol. 13, no. 13, 1999.

[10] Freitas-Vieira, J., Có, M., Zoral, L., High Power Factor Electronic Ballast Based on a Single Power Processing Stage, IEEE, PESC'95, pp 687-693, 1995

[11] Alonso, J.M., Calleja, A.J., Ferrero, F.J., Lopez, E., Ribas, J., Rico-Secades, M., Single-Stage Constant Wattage High Power Factor Electronic Ballast with Dimming Capability, IEEE, PESC'98, vol 2. 1998.

[12] do Prado, R.N., Bonalso, S.A., Greff, D.S., To High Power Factor Flyback-Half Bridge for Converter Fluorescent Lighting, IEEE, IECON'98, 1998. 
[13] Deng, e., Cuk, S., Single Stage, High Power Factor, Lamp Ballast, IEEE, APEC'94, 1994.

[14] Brioschi, R.O., Lamego, M.M., Vieira, L.F., A Low Cost High Power Factor Electronic Ballast, Proceedings of the IEEE Industry Applications Society Annual Meeting, 1997, pp. 2360-2365.

[15] Alonso, J.M., Calleja, A.J., Ribas, J., Lopez, E., Rico-Secades, M., A Novel Low-Cost High-Power-Factor Integrated Ballast for Fluorescent Lamps, Proceedings of the IEEE Industrial Electronics Conference IECON'97, pp.941-946.

[16] Alonso, M., Calleja, A., López, E., Ribas, J., RicoSecades, M., A Novel Single Stage Constant-Wattage High-Power-Factor Electronic Ballast, IEEE Transaction on Industrial Electronics, Vol. 46, No. 6, December 1999, pp. 1148-1158.

[17] Wu, T.F., Chiang, M.C., Chang, E.B., Analysis and Design of a High Power Factor, Single - Stage Electronic Ballast with Dimming Feature, Proceedings of the IEEE Applied Power Electronics ConferenceAPEC'97, pp. 1030-1036.

[18] do Prado, R.N., Bonaldo, S.A., Greff, D.S., A High Power Factor Flyback-Half-Bridge Electronic Ballast with Dimming Feature, Proceedings of the IEEE Industry Applications Conference Annual Meeting, 1998, pp. 2082-2088.

[19] Takahashi, N., Kato, Y., Ohkita, M., Okutso, K., Matsuyama, M., Nakaoka, M., Two Switch Boost Chopper-Based PFC Converter for Electronic Ballast, in Proceedings of the International Conference on Power Electronics and Drive Systems PEDS'99, pp. 511-515.

[20] Alonso, J.M., Villegas, P.J., Diaz, J., Blanco, C., Rico-Secades, M., A microcontroller-Based Ballast for Fluorescent Lamps, IEEE Transaction on Industrial Electronics, Vol. 44, No. 2, April 1997, pp. 207-216.

[21] Alonso, J.M., Ribas, J., Coz, J.J., Calleja, A.J., Corominas, E.L., Rico-Secades, M., Development of a Distributive Control Scheme for Fluorescent Lighting Based on LonWorks Technology, IEEE Transaction on Industrial Electronics, Vol. 47, No. 6, December 2000, pp. 1253-1262.

[22] Wu, T.F., Yu, T.H., An Electronic Dimming Ballast with Bifrequency and Fuzzy Logic Control, IEEE Transaction on Industry Application, Vol. 36, No 5, September/October 2000, pp. 1308-1317.

[23] Microchip Technology Inc., "PIC16C71 Reference Manual". 


\section{Authors' Biographies}

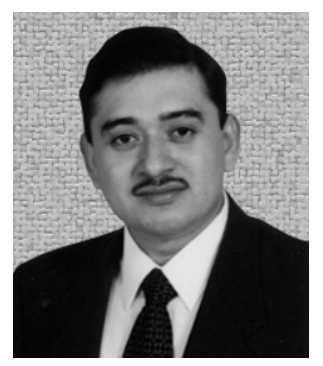

\section{Carlos AGUILAR-CASTILLO}

He received the B.E (electromechanical engineering) from the Instituto Tecnológico de Tuxtepec in Oaxaca, Mexico, and the M.Sc. and the Ph.D. (electronics) both from the National Center for Research and Technological Development (CENIDET), in Morelos, Mexico. Also, he was a visiting scholar (postdoctoral stay) at the Center for Power Electronics Systems (CPES) at the Virginia Polytechnic Institute and State University in Virginia, USA. He has been with the Electronics Department at CENIDET since 1995. His research areas are Illumination Systems, Cleaner Systems Based on Ultrasonic, Clean Electricity Generation Systems, and Low-power and Low-voltage DC to DC Converters.

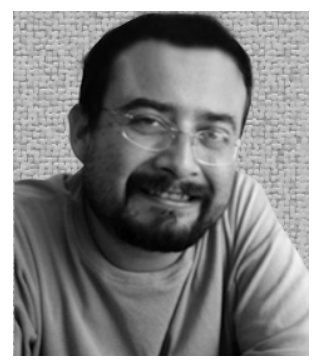

\section{Carlos D. GARCÍA-BELTRÁN}

He received a B.E (electronics) from the Universidad de San Luis Potosí in San Luis Potosí, Mexico, in March, 1992, the M. Sc. (electronics) from the National Center on Research and Technological Development, (CENIDET) in Morelos, Mexico and the Ph.D. degree in engineering from the INPG in Grenoble, France, in September, 2004. Since 1997, he has been a faculty member of the Electronics Department at CENIDET. His research areas are Intelligent Control, Fault Diagnosis, Fault Tolerant Control and Embedded Control Systems.

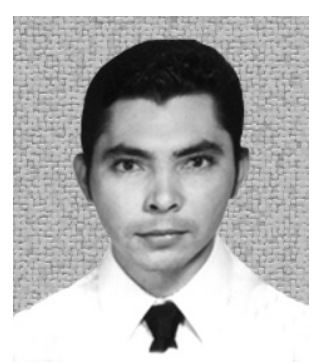

\section{Carlos MORCILLO-HERRERA}

He received a B.E (Electronics) from the Instituto Tecnológico de Mérida, Yucatán, Mexico, in 1998, the M. Sc. (Electronics) from the National Center on Research and Technological Development, (Cenidet), Cuernavaca, Morelos, México, in 2000. He is a faculty member of the Industrial Division, at the Universidad Tecnológica Metropolitana. Research areas: Power electronics. 